\title{
Prevalence and Pregnancy Outcome of Gestational Diabetes Mellitus Among Bangladeshi Urban Pregnant Women
}

\author{
MANNAN MA, ${ }^{1}$ RAHMAN MH, ${ }^{2}$ ARA I, ${ }^{3}$ AFROZ $\mathrm{H}^{4}$
}

\begin{abstract}
:
Objective: To assess the prevalence of gestational diabetes mellitus (GDM) among the pregnant women of Dhaka city and to find out the consequences or effects of GDM on pregnancy outcome.

Materials and methods: This was a descriptive type of cross sectional study followed by cohort type of study, conducted in different hospitals in Dhaka city. Initially 960 pregnant women of $24^{\text {th }}$ to $28^{\text {th }}$ weeks were selected purposively; plasma glucose was measured at fasting and two hours after taking $75 \mathrm{~g}$ oral glucose load. Modified method of Carpenter and Coustan criteria was followed to diagnose GDM. For each GDM case diagnosed, one non-GDM pregnant women was taken as control after matching age and parity. Both groups were followed up to 4 wks after delivery to find out maternal and neonatal mortality and morbidities.

Results: Out of 960 pregnant women 72 were GDM positive (7.5\%). There was no maternal mortality but morbidities like hydramnions $(p<0.001))$, pre-eclampsia $(p<0.001))$, urinary tract infection $(p<0.05)$, puerperial sepsis $(p<0.05))$ and surgical interventions $(p<0.001$ ) were more prevalent in GDM compared to non-GDM groups. The prevalence of antipartum haemorrhage, post partum haemorrhage, and eclampsia did not vary between the groups. There was one still birth, one perinatal mortality (due to respiratory distress syndrome) and one congenital anomaly observed in neonates of GDM mothers. More pre-term $(p<0.01)$, post-term $(p<0.01)$, low birth weight $(p<0.001)$ and macrosomic $(p<0.001)$ babies were found among the babies of GDM mothers than non-GDM mothers. More babies also suffered from neonatal jaundice $(p<0.05)$ and respiratory distress syndrome $(p<0.05)$ in GDM groups than non GDM groups.

Conclusion: The prevalence of GDM in urban Bangladeshi population is about 7.5\%. Maternal morbidities like hydramnios, pre-eclampsia, infections and operative interventions were observed more in GDM mothers. Pre-term, post-term and LBW babies alone with perinatal morbidities like respiratory distress syndrome, macrosomia and neonatal jaundice were more common in babies of GDM mothers.
\end{abstract}

Keyword: Gestational Diabetes Mellitus, maternal morbidities and neonatal morbidities.

\section{Introduction:}

Diabetes is one of the most important medical disorders encountered in pregnancy and affects each other adversely. ${ }^{1-}$ ${ }^{3}$ Any degree of glucose intolerance first time detected in pregnancy is called gestational diabetes mellitus G.DMS. ${ }^{1.4}$

1. Professor, Dhaka Medical College and Hospital, Dhaka-1000, Bangladesh,

2. Assistant Professor, Department of Endocrinology, Dhaka Medical College and Hospital, Dhaka-1000, Bangladesh,

3. Professor, Department of Gynaecology \& Obstetrics, Dhaka Medical College and Hospital, Dhaka-1000, Bangladesh,

4. Associate Professor, Gynaecology \& Obstetrics, Rashahi Medical College, Rajshahi, Bangladesh.

Correspondence : Professor Dr. MA Mannan, Department of Endocrinology, Dhaka Medical College and Hospital, Dhaka-1000, Bangladesh, Department of Endocrinology, Dhaka Medical College and Hospital, Dhaka-1000, Bangladesh. Tel. : 880-2-9898961, 8802-8834373,E-mail: drmadem@yahoo.com
The prevalence of GDM varies widely. In Caucasians it is 1$2 \%$, in Afro-Caribbeans 2-3\% and among Asians 4-5\%. 5-7 GDM is well known for its disastrous impact on the fetus in terms of perinatal mortality and morbidity and also on the mother for obstetrical complications. ${ }^{8-16}$

Hyperglycemia in the first trimester of pregnancy may lead to congenital malformations. Common malformations are anencephalus, hydrocephalus, spina bifida, caudal regression, ear and eye anomalies, ventricular septal defect, atrial septal defect, transposition of great vessels, and renal and rectal anomalies. So GDM is one of the important risk factors for perinatal and infant morbidity and mortality. ${ }^{16-23}$ In Bangladesh, 7-14\% women are the victims of diabetes in their reproductive age. ${ }^{24-25}$ Effects of gestational diabetes in mother and fetus produce important health hazards. Effects on mothers are abortion, repeated urinary tract infections, and increased incidence of pre-eclampsia (25\%), 
hydramnions (25-50\%), maternal distress, prolongation of labor (due to big baby), shoulder dystocia, perinatal injuries, post-partum heamorrhage, operative interference, puerperal sepsis, and failure of lactation; effects on fetus are foetal macrosomia (30-40\%), congenital malformation (6-8\%) and birth injury. Neonatal complications include hypoglycemia, respiratory distress syndrome, hyperbilirubinemia, polycythemia and hypocalcemia. ${ }^{7,11,17-23}$ The overall perinatal risk is increased 2-3 times in diabetics than the non-diabetics. ${ }^{18-20}$ The stillbirths are usually limited to the last four weeks of pregnancy and are more related to ketoacidosis of the mother or foetal hypoglycaemia. The neonatal deaths are principally due to foetal hypoglycaemia or respiratory distress syndrome. ${ }^{11-15}$

So detection of GDM cases are important so as to control their glycemic state to prevent these maternal and fetal complications. The present study was undertaken to detect the prevalence and complications of GDM.

\section{Materials and Methods:}

This was a descriptive type of cross sectional study followed by cohort study. After obtaining informed consent, a total number of 960 pregnant women of $24^{\text {th }}$ to $28^{\text {th }}$ weeks of gestational age were selected purposively during the study period. Patients with known diabetes before pregnancy, serious comorbid diseases or using drugs significantly affecting glucose metabolism were excluded. The purpose of the study was explained in details to each subject and informed written consent was taken.

Place and period of the study: The study was conducted in Sir Salimullah Medical College Hospital, Azimpur Maternity Center and some selected private hospitals in Dhaka city. The study period was one year duration from July,2006 to June,2007.

Determination of GDM: All pregnant women were screened for GDM in their $24^{\text {th }}$ to $28^{\text {th }}$ wks of gestation. Screening was done by sampling blood fasting and one and two hours after ingestion of 75 gram oral glucose solution. Modified method of Carpenter and Coustan criteria was followed. ${ }^{26}$ Blood glucose fasting $>5.3 \mathrm{mmol} / \mathrm{L}$ and $2 \mathrm{hr}$ after taking $75 \mathrm{gm}$ glucose drink $>8.6 \mathrm{mmol} / \mathrm{L}$ respectively were taken as a cut point for the diagnosis of GDM. Plasma glucose was measured by glucose oxidase method. For quality assurance, the sensitivity of the auto analyzer was checked before each run.

For follow up: After identifying the pregnant women with GDM, for each GDM pregnant women, one non-GDM pregnant women was taken as control after matching age and parity (Table-1). Both groups were followed up to $4 \mathrm{wks}$ early neonatal period to find out the association of GDM with maternal morbidity (like antepartum haemorrhage, polyhydramnios, pre-eclampsia, postpartum haemorrhage, urinary tract infection, postpartum haemorrhage, eclampsia, surgical intervention, and puerperal sepsis) and mortality as well as neonatal morbidity (like prematurity, postmaturity, low birth weight, large baby, still birth, macrosomia, congenital malformations, neonatal jaundice and respiratory distress syndrome) and mortality during the postnatal period.

Data processing \& analysis: After collecting data in prescribed form, data entry and analysis was done using SPSS program. Chi Squard $\left(\mathrm{X}^{2}\right)$ and other appropriate statistical tests were done. $\mathrm{P}$ values $<0.05$ were considered significant.

\section{Results:}

Out of 960 pregnant women of 24-28 weeks of gestation, 72 were found to have GDM and the prevalence rate was $7.5 \%$ Table-I. From the non-GDM subjects, 72 matched control subjects were selected Table-II and maternal and neonatal complications were compared.

Table-I

Frequency of GDM cases among pregnant women

\begin{tabular}{lcc}
\hline Diabetes status & Number of patients & Percentages \\
\hline GDM positive & 72 & 7.5 \\
GDM negative & 888 & 92.5 \\
\hline Total & 960 & 100 \\
\hline
\end{tabular}

Table-II

Matching characteristics of GDM and non GDM pregnant women

\begin{tabular}{lccccc}
\hline GestationalAge & \multicolumn{2}{c}{ GDM(n=72) } & & \multicolumn{2}{c}{ Non GDM $(\mathrm{n}=72)$} \\
\cline { 2 - 3 } \cline { 6 - 6 } & No & $\%$ & & No & $\%$ \\
\hline $24^{\text {th }}$ week & 13 & 18.0 & & 13 & 18.0 \\
$25^{\text {th }}$ week & 14 & 19.4 & & 14 & 19.4 \\
$26^{\text {th }}$ week & 13 & 18.0 & & 13 & 18.0 \\
$27^{\text {th }}$ week & 15 & 20.8 & & 15 & 20.8 \\
$28^{\text {th }}$ week & 17 & 23.4 & & 17 & 23.4 \\
Parity ofsubjects & & & & \\
Primipara & 17 & 23.4 & & 17 & 23.4 \\
Para-2 & 24 & 33.3 & & 22 & 30.6 \\
Multipara & 31 & 43.3 & & 31 & 43.3 \\
Age groups (yrs) & & & & \\
$15-25$ & 50 & 69.5 & & 34 & 47.2 \\
26.35 & 17 & 23.6 & & 35 & 48.6 \\
$36-45$ & 5 & 6.9 & 3 & 4.2 \\
\hline
\end{tabular}


There was no maternal mortality in both groups. But morbidities more prevalent in GDM patients than controls were polyhydramnions $(33.3 \%$ vs $2.8 \%, \mathrm{p}<0.001)$, preeclampsia ( $25 \%$ vs $1.4 \%, \mathrm{p}<0.001)$, urinary tract infection ( $18.1 \%$ vs $4.2 \%, \mathrm{p}<0.05$ ), surgical intervention (like lower uterine caesarian section) $(48.6 \%$ vs $13.9 \%, \mathrm{p}<0.001)$ and puerperal sepsis $(19.4 \%$ vs $4.2 \%, p<0.05)$, but the prevalence of antipartum haemorrhage, post partum haemorrhage (PPH), and eclampsia did not vary between the groups Table-III.

Table-III

Distribution of maternal complications in GDM and non GDM groups

\begin{tabular}{lllllll}
\hline Variables & \multicolumn{2}{c}{ GDM } & & \multicolumn{2}{c}{ Non GDM } & Level \\
\cline { 2 - 3 } & No & $\%$ & & No $\quad \%$ & significance \\
\hline
\end{tabular}

Before delivery

\begin{tabular}{|c|c|c|c|c|c|}
\hline \multicolumn{6}{|c|}{$\mathrm{APH}$} \\
\hline Yes & 2 & 2.8 & 1 & 1.4 & NS \\
\hline No & 70 & 97.2 & 71 & 98.6 & \\
\hline \multicolumn{6}{|c|}{ Hydramnios } \\
\hline Yes & 24 & 33.3 & 2 & 2.8 & $\mathrm{p}<0.001$ \\
\hline No & 48 & 66.7 & 71 & 97.2 & \\
\hline \multicolumn{6}{|c|}{ Pre-Eclampsia } \\
\hline Yes & 18 & 25 & 1 & 1.4 & $\mathrm{p}<0.001$ \\
\hline No & 54 & 75 & 71 & 98.6 & \\
\hline \multicolumn{6}{|l|}{ UTI } \\
\hline Yes & 12 & 18.1 & 3 & 4.2 & $\mathrm{p}<0.05$ \\
\hline No & 59 & 81.9 & 69 & 95.8 & \\
\hline \multicolumn{6}{|c|}{ At delivery } \\
\hline \multicolumn{6}{|c|}{ PPH } \\
\hline Yes & 10 & 13.9 & 8 & 11.1 & $\mathrm{p}>0.05$ \\
\hline No & 62 & 86.1 & 64 & 88.6 & \\
\hline \multicolumn{6}{|c|}{ Eclampsia } \\
\hline Yes & 2 & 2.8 & 1 & 1.4 & NS \\
\hline No & 70 & 97.2 & 71 & 98.6 & \\
\hline \multicolumn{6}{|c|}{ Surgical interference } \\
\hline Yes & 35 & 48.6 & 10 & 13.9 & $\mathrm{p}<0.001$ \\
\hline No & 47 & 51.4 & 60 & 86.1 & \\
\hline \multicolumn{6}{|c|}{ After delivery } \\
\hline \multicolumn{6}{|c|}{ Puerperal sepsis } \\
\hline Yes & 14 & 19.4 & 3 & 4.2 & $\mathrm{p}<0.05$ \\
\hline No & 58 & 50.6 & 69 & 95.8 & \\
\hline
\end{tabular}

There was only one still birth in GDM group (Table-IV). One perinatal mortality due to respiratory distress syndrome and one congenital anomaly were also observed in neonates of GDM mothers. Increased number preterm (16.7\% vs $4.2 \%$, $\mathrm{p}<0.01)$, post term $(6.9 \%$ vs $4.2 \%, \mathrm{p}<0.01)$ and low birth weight (29.2\% vs 8.3\%, p $<0.001)$ babies were found in GDM group than control group. More babies also suffered from neonatal jaundice $(22.2 \%$ vs $8.4 \%, \mathrm{p}<0.05)$, fetal macrosomia $(13.9 \%$ vs $2.8 \%, \mathrm{p}<0.001)$ and respiratory distress syndrome $(11.1 \%$ vs $4.17 \%, \mathrm{p}<0.05)$ in GDM groups than non GDM groups.

Table-IV

Distribution of foetal and neonatal outcome in GDM and non GDM groups

\begin{tabular}{lllllll}
\hline Variables & \multicolumn{2}{c}{ GDM } & & \multicolumn{2}{c}{ Non GDM } & Level \\
\cline { 2 - 3 } & No & $\%$ & & No & $\%$ & significance \\
\hline
\end{tabular}

Termination

Pre-term

$\begin{array}{lllll}12 & 16.7 & 3 & 4.2 & \text { NS } \\ 5 & 6.9 & 3 & 4.2\end{array}$

Birth weight

$<2.5 \mathrm{~kg}$ (low BW) 21

$>3 \mathrm{~kg}($ Large-B)

29.17

6

$8.3 \quad \mathrm{p}<0.001$

Still birth

Yes

$\begin{array}{ccccc}18 & 1.4 & 00 & 00 & \mathrm{p}<0.05 \\ 71 & 98.6 & 72 & 100\end{array}$

Perinatal mortality

$\begin{array}{cccccc}\text { Yes } & 1 & 1.4 & 00 & 00 & \mathrm{p}<0.05 \\ \text { No } & 71 & 98.6 & 72 & 100 & \end{array}$

Jaundice

$\begin{array}{cccccc}\text { Yes } & 16 & 22.2 & 6 & 8.4 & \mathrm{p}<0.05 \\ \text { No } & 56 & 77.8 & 66 & 91.6 & \end{array}$

Congenital Malformation

$\begin{array}{cccccc}\text { Yes } & 1 & 1.39 & 00 & 00 & \mathrm{p}<0.05 \\ \text { No } & 71 & 98.61 & 72 & 100 & \end{array}$

Foetal macrosomia

$\begin{array}{cccccc}\text { Yes } & 10 & 13.9 & 2 & 2.8 & \mathrm{p}<0.001 \\ \text { No } & 62 & 80.1 & 70 & 97.2 & \end{array}$

Respiratory distress syndrome

\begin{tabular}{lccccc} 
Yes & 08 & 11.1 & 3 & 4.17 & $\mathrm{p}<0.05$ \\
No & 64 & 88.9 & 69 & 95.83 & \\
\hline
\end{tabular}




\section{Discussion:}

Earlier research has shown that pregnant women with diabetes have an increased risk of developing obstetric complications, ketoacidosis, hypoglycemia and micro vascular complications. In the present study, there was no maternal mortality but morbidity like hydramnoions, preeclampsia, infections like UTI, puerperal sepsis were more in the GDM women than the non-GDM women and is in accordance with others studies. ${ }^{21}$ More maternal infections during pregnancy in the GDM women was explained by different authors as due to lower immunity.

In our study, the rate of delivery by caesarian section was more in GDM group. However complications associated with GDM such as fetal macrosomia or maternal hypertension may increase the likelihood of caesarian section. Because macrosomia is associated with shoulder dystonia, it is particularly important to diagnose it before labor. ${ }^{1-3}$

There were more macrosomic babies in GDM group than non-GDM subjects in our study. Normally fetal pancreas is relatively unresponsive to physiological levels of glucose. When maternal hyperglycemia is present (as in GDM), the fetus responds to elevated glucose levels by beta cell hypertrophy and there is increased production of insulin in utero. Insulin acts as a growth factor in the fetus. This hyperinsulinemia and hyperglycemia lead to an increase in organ size and total adipose tissue mass and subsequent fetal weight gain. Macrosomia is probably the most widely known complication affecting the fetus of diabetic women. A consequence of the increase size of the infant is an increased caesarian section rate also.

In the neonates, the respiratory distress syndrome was observed more $(\mathrm{P}<0.01)$ in the babies of GDM mothers than the babies of non-GDM mothers in our study. The increased incidence of respiratory distress syndrome has long been noted with many factors such as the increased incidence of prematurity and caesarian section delivery. Some studies have suggested that polyhydramnions associated with diabetic pregnancy may contribute to decreased lung lecithin level and that maternal diabetes itself may lead to some abnormality in lecithin synthesis and metabolism in the fetus. ${ }^{7,11,15}$ However, these factors remain unclear and require further investigation.

Several studies have concluded that the rate of perinatal mortality (including stillbirths and neonatal deaths) was increased in women with GDM in the past. ${ }^{27-29}$ In the present study, there is one still birth and one perinatal mortality in GDM group.
There is increased preterm and low birth weight babies in GDM mother in our study. Increased prevalence of low birth weight is due to placental vascular insufficiency.

Infants born to diabetic mother are 4 times more likely to have congenital anomalies of the brain, heart, kidney, intestine and skeleton. ${ }^{30}$ These complications occur in the periconceptional period, due to raised blood glucose. In the present study, in GDM group, one congenital anomaly was seen. Macrosomia occurs in $<20-30 \%$ of infants whose mothers have GDM. ${ }^{31}$ The excess glucose and the resulting hyperinsulinemia stimulate fat storage and leads to macrosomia. Fetal macrosomia is increased in babies of GDM mother in our study.

The primary respiratory problem in infants of GDM mother is respiratory distress syndrome (RDS). This is caused by surfactant deficiency or by retained fetal lung fluid. RDS occurs more in infants of diabetic mothers due to the lack of maturity in the type II alveolar cells. ${ }^{32}$ In our study, prevalence of RDS is more in babies of GDM mother.

Jaundice was seen more $(\mathrm{P}<0.05)$ in babies of GDM mothers than the babies of non-GDM mothers in our study. It is probably related to a decreased ability of the liver to conjugate bilirubin resulting from the breakdown of the increased volume of red blood cells. ${ }^{13,17,33}$

So, in conclusion, the study result shows the prevalence of GDM in urban Bangladeshi population is about 7.5\%. Maternal morbidities like hydramnios, pre-eclampsia, UTI, pueroerial sepsis were observed more in GDM mothers. Delivery by Cesarean section was also more common in pregnant women with GDM. Pre-term, post-term and LBW babies alone with perinatal morbidities like respiratory distress syndrome, macrosomia and neonatal jaundice were more common in babies of GDM mothers.

\section{Conflict of Interest : None}

\section{References:}

1. Metzger BE, Coustan DR (Eds): Proceedings of the Fourth International Workshop Conference on gestational diabetes mellitus. Diabetes Care 1998; 21(Suppl): B 1-167.

2. Expert committee on the diagnosis and classification of diabetes mellitus. Diabetes care 2002;25(Suppl.1)5-20.

3. Sayeed MA, Mahtab H, PA Khanam, STE Amin and Khan Ak. The prevalence of gestational diabetes mellitus in a rural community of Bangladesh. Diabetologia 2001; 44(S);A 106.

4. American College of Obstetricians and Gynaecologists. Gestational Diabetes, Practice Bulletin no. 2001; 30.

5. Second International Workshop conference on Gestational Diabetes Mellitus: Summary and Recommendations. Diabetes 1985; 34(Suppl 2): 123-126. 
6. Ferinkel N: GDM and perinatal outcome. Diabetes 1985; 34(Suppl): 24-27

7. Beischer NA. Effect of follow up of women with gestational diabetes on the ratio of IDDDM to NIDDM in pregnancy. Diabetes Care 1996; 19(6): 633-55

8. Coustan DR. Gestational Diabetes. Doabetes Care 1993; 10(3): $8-15$

9. Blank A. Effects of gestational diabetes on perinatal morbidity reassessed. Report of the International Workshop on Adverse Perinatal Outcomes of Gestational Diabetes Mellitus, Dec. 3-4, 1992. Diabetes Care 1995; 18(1): 127-29

10. Vohr BR. Effects of maternal gestational diabetes and adiposity on neonatal adiposity and blood pressure. Diabetes Care. 1995; 18(4): 467-475

11. Silverman B L. Impaired glucose tolerance in asolescent offspring of diabetic mothers. Relationship to feta hyperinsulinism. Diabetes Care 1995; 18(5): 611-617

12. Beischer NA. Maternal glucose tolerance and obstetric complications in pregnancies in which the offspring developed type 1 diabetes. Diabetes care, 1994; 17(8): 834-834

13. Viskianathan M, Viswanathan V, and Ramachandran F. Observation on NIDDM in India. Symposium on Gestational Diabetes: Conference recommendations. Diabetes Care. 1980; 3: 499-501

14. Mahtab H, Ibrahim M, Banik MG, Gulshan -E-Jahan. Diabetes detection survey in a rural and semi urban community in Bangladesh. Tohokul J Exp Med. 1983; $141: 211-217$

15. Munirul Haque, Zafar Ahmed Latif and Hajera Mahtab; Screening for gestational diabetes mellitus. J diab Assoc Bandg $1992 ;(2) 6-14$

16. Sayeed MA. Khan AR Hoque F, Ahmed T, Rahman M, Banu A. Prevalence of diabetes mellitus in Dhaka city. A preliminary study. J Diab Assoc Bangladesh 1992; 20(2): $17-22$

17. Sayeed MA, Khan AR, Mahtab H, Mahtab F, Banu A. Several discrete studies on prevalence of diabetes in Bangladesh. J Diab Asso. Bangladesh 1993; 21(1): 21-28

18. Sayeed MA, Hussain MZ, Banu A, Rumi MAK and Khan AK. Prevalence of diabetes in a suburban population of Bangladesh. Diab Res Clin pract 1997; 34: 149-155
19. National Diabetes Data Group (NDDG): Classification and diagnosis of diabetes mellitus and other categories of glucose intolerance. Diabetes 1979; 24:1039-59

20. Landon M, Gabbe S. Diabetes mellitus and pregnancy. Obstet Gynaecol. Clin North Am 1992; 19: 633-54

21. Edward, g. Lufkin, roger. L. nelson, et al. An analysis of diabetic pregnancies at Mayo clinic. Diabetic Care 1984; 7: $539-47$

22. Karalus N.C. Dunn P.J. Haslam a. J. Outcome of diabetic pregnancies in Waikato Five year experience. The New Zealand 1985; 98:369-71

23. Plehwe, W E. Shearman R. P and Turtle J.R. Outcome of pregnancy complicated by diabetes; experience with 232 patients in a 4 year period. Diabetic Research 1984; 1(2): $67-73$

24. Fuhrmann K. Reiher H. semmler K. Prevention of congenital malformation in infants of insulin dependent diabetic mothers. Diabetic Care. 1983; 6:219-23

25. Carpenter MW, coustan DR: Criteria for serecring tests for gestational diabetes. Am J obstet Gynaecol 1982; 144: $768-773$

26. American diabetes association: gestational diabetes mellitus. Diabetes care 2000; 23: 77-79

27. O'Sullivan JB, Charles D, Mahan CM, Dandrow RV: Gestational diabetes and perinatal mortality rate. Am J Obstet Gynecol 116:901 -904, 1973

28. Beischer NA, Wein P, Sheedy MT, Steffen B: Identification and treatment of women with hyperglycaemia diagnosed during pregnancy can significantly reduce perinatal mortality rates. Aust NZ J Obstet Gynecol36 : 239-247,1996

29. Wood SL, Sauve RS, Ross S, Brant R, Love E: Prediabetes and perinatal mortality. Diabetes Care 23:1752 -1754, 2000

30. Kalhan SC, Parimi PS, Lindsay CA: Pregnancy complicated by diabetes mellitus. In Fonaroff AA, Martin RJ (eds): Neonatal-Perinatal medicineDisease of the Fetus and infant, $7^{\text {th }}$ ed.Philadelphia, Mosby,2002, p 1357

31. Kjos AL, Buchanan TA: Gestational diabetes mellitus. N Eng1 J Med341 : 1749-1756,1999

32. Nold JL, Georgieff MK: Infants of diabetic mothers.Pediatr Clin North Am 51:619-637, 2004 